\title{
Jolanta CHOMKO
}

Uniwersytet w Białymstoku jchomko@interia.pl

\section{СЕМАНТИЧЕСКОЕ ПРОСТРАНСТВО КАЮЧЕВОГО С ОВА-РЕПРЕЗЕНТАНТА КОНЦЕПТА «ВО $\Delta A »$ В РУССКОМ ЯЗЫКЕ (СИНОНИМИЯ)}

Развитие когнитивной лингвистики связано с разработкой многоуровневой теории значения слова - когнитивной семантики. Отличительной особенностью когнитивной семантики, по мнению ученых, является «выход за пределы собственно языковых знаний и обращение к знаниям неязыкового, энциклопедического характера, а также определение роли этих знаний в процессе фрормирования языковых значений и смысла высказывания» 1 . Н. Н. Болдырев считает, что «языковые значения передают лишь некоторую часть наших знаний о мире. Основная же доля этих знаний хранится в нашем сознании в виде различных мыслительных структур - концептов разной степени сложности и абстрактности, в содержание которых могут постоянно включаться новые характеристики» ${ }^{2}$. Понятию концепта - ментального комплекса, репрезентированного средствами языка, посвящены большое количество работ, как теоретического плана (Алефиренко ${ }^{3}$, Колесов $^{4}$, Попова, Стернин ${ }^{5}$ и др.), так и описательного (Степанов ${ }^{6}$, Воркачев ${ }^{7}$, Маслова $^{8}$ и др.).

\footnotetext{
1 Хантимиров С. М., 2009, Экстралингвистический компонент семантики слова, Вестник ВЭГУ, № 3, с. 106.

2 Болдырев Н. Н., 2001, Кониепт и значение слова, (в:) Методологические проблемь когнитивной лингвистики, Воронеж, с. 27.

3 Алефиренко Н. Ф., 2005, Спорные проблемы семантики, Москва.

4 Колесов В. В., 2002, Философия русского слова, Санкт-Петербург.

5 Попова З. А., Стернин И. А., 2001, Очерки по когнитивной лингвистике, Воронеж.

6 Степанов Ю. С., 2001, Константьл. Словарь русской культурьи, Москва.
} 
Концепты могут быть независимыми от языка, и не все концепты могут фиксироваться языковыми средствами, но самые важные концепты кодируются именно в языке. Предметом анализа в статье является конщепт «вода», который относится к числу последних. Этот концепт имеет немаловажное значение для всей концептосферы в целом, так как вода имеет огромное значение в жизни человека и - шире - в жизни на Земле. Она является главной составляющей гидросферы (океанов, морей, рек и т. А.), находится в верхней части земной коры (подземные воды), содержится в почве, многих минералах, горных породах, а также является непременной составной частью живых организмов. Человек, а также другие живые существа способны выделять специфическую влагу - пот, испарину, слюни, слезы.

На Земле постоянно происходит процесс обращения воды (круговорот воды в природе). Этот процесс происходит, в частности, благодаря способности воды к испарению и конденсации. Вода выпадает на земную поверхность в виде осадков (дождевая вода).

Воду пьют люди, животные и растения. Она составляет одно из непременных условий их жизнедеятельности: ее кратковременное отсутствие вызывает болезненное состояние, а длительное - приводит к смерти (питьевая вода, умереть от жаждь, объявить сухую голодовку).

Человек использует воду в разных бытовых и производственных целях, например, для подлержания чистоты, для орошения, в качестве катализатора химических процессов и т. д. (техническая вода, тяжелая вода).

То значение, которое имеет вода в жизни человека, находит отражение в метафорической активности слова. Аексема вода входит в устойчивые сочетания и выражения, используюшиеся для характеристики различных сторон жизни человека: его внешнего вида (быть похожим как две капли водь 'о полном, обычно внешнем, сходстве лиц, предметов, явлений'); внутреннего и внешнего состояния (бъть точно «как» в воду опущенным 'находиться в состоянии душевной подавленности, угнетенности, быть чем-то очень расстроенным'); поведения (бъть как рыба в воде 'чувствовать себя

7 Воркачев С. Г., 2004, Сиастье как лингвокультурный концепт, Москва; Воркачев С. Г., 2007, Аюбовь как лингвокультурный концепт, Москва.

8 Маслова В. А., 2007, Введение в когнитивную лингвистику, Москва. 
где-либо совершенно свободно, вполне естественно, просто и непринужденно'); речевого поведения (как воды в рот набрать 'будто онеметь, лишиться способности говорить (об упорном молчании, о нежелании говорить)', лить воду 'лгать; говорить пустое, пустословить'); характера (как с гуся вода 'ничего не действует на кого-либо, не производит никакого впечатления на кого-либо', воды не замутит 'кто-либо очень скромен, тих, смирен, человек, который не причинит никому ни малейшего зла, ни малейшей обиды'); поступков и деятельности (выводить «вывести» на иистую «свежую» воду 'разоблачать, уличать кого-либо; раскрывать дела, обычно темные, неблаговидные', (с)прятать конци в воду 'избавляться от улик совершенного преступления, проступка, уничтожая их следы', ловить рыбу в мутной воде 'пользуясь неясностью обстановки, разногласиями, извлекать выгоду из чьих-либо затруднений', толочь воду в ступе 'занимаясь чем-либо бесполезным, напрасно тратить время', носить воду решетом 'заниматься бессмысленной, бесполезной работой', идти в огонь и в во$\partial y$ 'идти на любой самоотверженный поступок, жертвуя всем', лить воду на иъю-то мельницу 'своими действиями, поведением, косвенно помогать кому-либо (чаще противнику)'); результатов поступков или деятельности (выйти сухим из воды 'избегать заслуженного наказания; оставаться безнаказанным (о хитрых, ловких людях)'); степени родства с другими людьми (седьмая вода на киселе 'человек, находящийся в крайне отдаленном родстве с кем-либо'); отношений с другими людьми (водой не разольешь 'очень дружны, в тесной дружбе; неразлучны, всегда вместе', возить воду на ком 'взваливать на кого-либо тяжелую, непосильную работу; обременять работой кого-либо'); воздействий на других людей (холодной водой окатить «облить» 'охладить чей-либо пыл, рвение; привести в замешательство кого-либо', утопить в ложке воды 'по незначительным, пустяковым причинам причинять зло, неприятности'); жизненного опыта (иройти огонь, воду и меднъге трубы 'пройти все мыслимые испытания, которые только могут встретиться в жизни человека', $u$ в воде (не) тонуть и в огне (не) гореть 'истину нельзя скрыть, она обнаружится, как бы ее ни прятали.'). Отдельные устойчивые выражения формулируют правила поведения (не зная броду, не суйся в воду 'не предпринимай чего-либо без знания дела', под лежачий камень вода не течет 'у того, кто не пытается что-либо сделать, ничего не получится'), отношения к людям (с лица воды не пить 'кто-либо должен быть снисхо- 
дителен к недостаточной привлекательности, красоте жениха или невесты') или характеризуют явления и события (по воде вилами писано 'неизвестно, сбулется ли желаемое, предполагаемое; это еще маловероятно, едва ли осушествимо', буря в стакане водь 'волнения, споры из-за пустяков').

Языковая метафорика водъл может быть связана с ее природными свойствами. Так, например, ее быстрое движение ассоџиируется с течением времени (много «сколько» водь утекло 'много времени прошло; произошло немало перемен с каких-либо пор'), беззвучность движения - с молчанием, спокойствием ((бътьь) тише водь, ниже травы 'очень тихий, смиренный'), прозрачность - со способностью видеть и понимать то, что скрыто в глубине (как в воду смотреть «глядеть» 'предвидеть, предугадать, знать заранее').

Иексема вода входит в ряд устойчивых словосочетаний и выражений, в которых «прочитываются» древние народные представления о ней. В древности к воде, являвшейся, согласно народным представлениям, одной из первых стихий мироздания наряду с землей, воздухом и огнем, отношение было двойственным.

С одной стороны, она признавалась средой обитания нечистой силы, духов, а также душ умерших людей, опасной для человека (как в воду кануть 'сгинуть, исчезнуть, пропасть бесследно, без вести', как водой смыло 'кто-либо мгновенно исчез, быстро удалился откула-либо.'). С другой сторны, в воде вилели средство воскрешения и очищения (живая вода 'мифическая чудодейственная жидкость, возвращаюшая жизнь мертвому телу', спрыснуть живой «мертвоц̆, святой» водой, живительная влага).

Аля исследования семантики и структуры конщепта важно понятие «конщептуальной модели», введенное И. П. Михальчуком и понимаемое им как способ экспликации семантической структуры концепта. «Моделирование концепта включает, таким образом, определение базовых компонентов его семантики, а также выявление совокупности устойчивых связей между ними» 9 . При создании концептуальной модели принщипиально важен прежде всего собственно семасиологический анализ лексемы, номинирующей конщепт. Значимо также рассмотрение семантики лексем, составляющих ассо-

9 Михальчук И. П., 1997, Кониептуальные модели в семантической реконструкции (индоевропейское понятие «закон»), Известия РАН, т. 56, № 4, с. 29. 
циативно-смысловое поле концепта. Следовательно, при описании конщепта наибольшее внимание надо обратить, во-первых, на семантическую структуру и этимологию слова-номинанта конщепта; во-вторых, на семантические, парадигматические и деривационные связи этой лексической единищы как наиболее значимой для вербализации анализируемого ментального комплекса; в-третьих, на набор, количество и семантику лексем, вербализующих концепт, причем значимость какой-либо составляющей анализа конщепта определяется прежле всего спецификой этого концепта ${ }^{10}$. Таким образом, исследуя содержание и структуру концепта, нельзя не обратиться к анализу синонимов ключевого слова. Анализ синонимов ключевого слова, вербализующего концепт «вода» в языке, дает возможность выявить дифференщиальные признаки данного концепта, появляюшиеся при сопоставлянии лексем, приналлежащих к синонимическому рялу.

В 4-х томном Словаре русского язюка ${ }^{11}$ дается следуюшая словарная дефинищия слова вода: 1. Прозрачная, бесцветная жилкость, образуюшая ручьи, реки, озера, моря и представляюшая собой химическое соединение водорода с кислородом (речная вода; морская вода; стакан водъ) // с определением. Напиток или водный раствор какого-л. вешества, применяемый для утоления жажды, а также в лечебных или иных целях (фруктовая вода; газированная вода; баталинская вода; туалетная вода); 2. Минеральные источники; 3. объчно мн. и. Водная масса реки, озера, моря // мн. и. Водные пространства, участки морей, озер, рек; 5. Чистота окраски, блеска, прозрачности драгоценного камня; 6. мн. и. Разг. То же, что околоплодные воды.

Стилистически нейтральным синонимом лексемы вода, зафиксированным в Словаре синонимов русского язика 12 , является лексема влага, которая в МАС определается как: Жидкость, вода // Сырость. К синонимам ряда примыкают также разговорно-шутливая номинация аш-два-о и штамп, использующийся в журналистике, бельй уголь. В письменных текстах для номинации данной жилкости может также использоваться химическая формула $\mathrm{H}_{2} \mathrm{O}$.

Синонимы анализируемого синонимического ряда сближаются со своим гиперонимом жидкость 'вешество, обладающее свойством

10 Рудакова А. В., 2004, Когнитология и когнитивная лингвистика, Воронеж, с. 61-69.

11 Словарь русского языка: В 4-х т. (МАС), 1999, ред. А. П. Евгеньева, Москва.

12 Словарь синонимов русскога языка. Практический справочник, 1989, ред. З. Е. Александрова, Москва. 
течь и принимать фрорму сосуда, в котором оно находится' (Минут через пятнадиать он вернулся сполньм иугунком картошки, банкой соленых огуриов и бутьлкой голубоватой жидкости (Ф. Незнанский, Ярмарка в Сокольниках); Из-под навоза, особенно после дождей, текла руиьями бурая зловонная жидкость прямо через весь двор (В. Гиляровский, Москва и москвичи); А на соседнем заводе спирт для меня из тормозной жидкости выделяют (М. Жванецкий, Миниатюры)).

Синонимы вода и влага различаются по следуюшим смысловым признакам: 1) количество жидкости (влага обычно преполагает незначительное количество жидкости, распределенное на небольшие порции); 2) способность обозначать содержимое водоемов (более характерна для синонима вода); 3) способ использования (вода используется для мытья, очистки, орошения, а также для промышленных целей); 4) способность обозначать жидкость, пропитывающую объект или являюшуюся одним из его компонентов (более характерна для вляги); 5) способность двигаться (более характерна для воды, которая может двигаться с большой скоростью, причем движение воды сопровождается специфическим звуком); 6) тип восприятия (Аля воды характерно восприятие на слух, а для влаги - на ощупь); 7) коннотации (влага в природе может ассоциироваться с свежестью и прохладой); 8) способностью к употреблению в специальных текстах (лексема влага используется в метеорологии).

Цексемы вода и влага имеют по два круга употреблений, выступая в качестве синонимов только в первом круге. В первом круге употреблений синонимы обозначают жидкую субстанцию естественного происхождения, в обычном состоянии не имеющую цвета и запаха.

Синоним вода является основной номинацией для обозначения данной субстанции как таковой, например: Вся вода на земной поверхности имеет исключительно внутрипланетарное происхождение, она «производилась» (...) в ходе геологической әволюиии планеть (Уппсальский корпус); Район освоенный, есть люди, жилье, дороги, вода (Уппсальский корпус). Синониму влага такое употребление несвойственно, однако, встречаются стилистически отмеченные примеры употребления слова влага для обозначения субстанции, например: Bот сейиас я подумал, ито влаге можно поклоняться, как поклонялись огню (И. Бунин, Тишина).

Воду пьют, а также используют для различных бытовых и промышленных целей, например: Жара, сушь и так сохнет во рту, ито 
даже вода освежсает только на минуту (Ю. Аомбровский, Факультет ненужных вещей); Он сел на ступеньке и намылил свои длинные волосы и шею, и вода около него стала коричневой (А. П. Чехов, Крыжовник); Электролиз в приниипе очень прост: в әлектролит (...) (классический вариант - вода с небольшим количеством щелочи), помещают два әлектрода и подводят к ним напряжение (Уппсяльский корпус). Влагу можно использовать только для питья, например: Боже мой! - в минуту огненной жажды видеть перед собою благотворную влагу, которая приближаясь к губам, засыхает (М. Ю. Аермонтов, Вадим).

Синоним вода может указывать на любое количество субстанции, как малое, так и значительное, например: Она изредка останавливалась, наклонялась и с забавной важностью роняла несколько капель воды, ярко блестевших на солнце (И. С. Тургенев, Ася); Вода сплошной пеленой валила за окном (М. Булгаков, Мастер и Маргарита).

Поскольку количество водь может быть сколько угодно большим, с ней может быть связано представление об опасности, например: бояться воды. Вода может также представлять опасность для человека, когда он находится в водной среде, например: Пароход медленно тонул, трюмы уже были залить водой (Николаева, МАС). Кроме того, синоним вода исползуется, когда речь идет о мощной струе или потоке, Авижущемся с большой скоростью и способном производить механические разрушения, например: Вода несется «миится», сметая все на своем пути; Вода обрушилась так страшно, ито когда солдать бежали к низу, им вдогонку уже летели бушующие потоки (М. Булгаков, Мастер и Маргарита).

Синоним влага, в свою очередь, обычно указывает на небольшое количество жидкой субстанщии, типичным является словосочетание капелька «капля» влаги. Влага чаще всего ассоциируется с мелкими каплями, появившимися на объектах, - прежде всего, на растениях и на почве, - после дождя или в вечерние, ночные или утренние часы, поэтому с этим синонимом связано представление о свежести и прохладе, например: Ты хочешь царствовать поньне, / Поэта дух воспламенять / И зноя полную пустьню / Росистой влагой освежать? (А. Блок, Ты хочешь царствовать поныне). Словосочетания типа много влаги, обильная влага указывают обычно на размер поверхности, покрытой влагой, например: На следующее утро солнце сверкает на мокрых листьях деревъев, на траве, на стеблях оживщей от обильной влаги кукурузи (Ф. Искандер, Сандро из Черема). 
Влага, так как и вода, может разрушать или портить объект, когда попадает внутрь его, что приводит к внутренним механическим повреждениям, или же при длительном контакте с объектом (подтачивая его, вызывая его гниение или коррозию), например: B иасы попала влага, и их пришлось нести в мастерскую; Ткань совершенно сгнила от влаги; Со временем о ней вообще забыли и вспомнили лишь тогда, когда влага от земляного бастиона начала разрушать стены некогда восстановленной части церкви (Уппсальский корпус).

Оба синонима используются для обозначения содержимого водоемов. Вода употребляется для обозначения жидкости, содержащейся в искусственных водоемах или образующей естественные водоемы - ручьи, озера, реки, мора, океаны, например: Он возвращался к себе, спал до пяти и уходил в плавательный бассейн; в талселой зеленоватой воде он ощущал свое тело особенно радостно (Ю. Семенов, Пресс-центр. Анатомия политического преступления); Морская вода содержит практически неисиерпаемые запасы редких металлов (Уппсальский корпус).

Синоним влага для обозначения содержимого водоемов употребляется значительно реже, и такое употребление является стилистически отмеченным, например: Студеная влага с легким шумом всплескивала, порою озаряясь фосфорическим блеском (М. Ю. Аермонтов, Вадим); А ньгиче, говорит, все только мертвець пльвут, гроздями пльвут видимо-невидимо, а влага речная ито руда, густал теплая, липкая; дьимать нечем (В. Набоков, Нежить); Уже на домах веют фрлаги, / Готовы новые птениь, / Но тихи струи невской влаги, / И слепь темные двориь (А. Блок, Вися на городом всемирным).

Слово влага используется также, когда речь идет о субстанции, пропитываюшей объект и являюшейся ее компонентом, например: Простую начинку, к тому же содержсащую достаточно собственной влаги, (...) можно либо вовсе не закрьввать, если пирог невелик, либо перекрьгвать плетенкой из теста (В. Похлебкин, Национальные кухни маших народов). Аексема вода может использоваться подобным образом в специальных контекстах, например: Организм иеловека содержит воды около 65\% (Энциклопедический словарь), однако в целом такие употребления ей несвойственны.

Вода в большей степени, чем влага, обладает способностью двигаться. Авижение воды, особенно если оно происходит с большой скоростью, может сопровождаться спесифическими звуками: журчанием, бурлением, гулом и т. А., например: Вода булькала, позванивала, 
журиала (К. Паустовский, Наедине с осенью); Аождь переставал временами, а вода с тихим плеском продолжала стекать вниз по листве и желобам (Б. Пастенак, Аоктор Живаго); Гроза бушевала с полной силой, вода с грохотом и воем низвергалась в канализационные отверстия, всюду пузырилось, вздувались волны, с крыи хлестало мимо труб, из подворотен бежали пенные потоки (М. Булгаков, Мастер и Маргарита). $\Delta$ ля синонима влага отчетливое звуковое сопровождение движения нехаряктерно.

Наличие воды легко обнаруживается при зрительном восприятии, причем даже с далекого расстояния, или же на слух, тогда как в наличии влаги чаще убеждаются при зрительном восприятии с близкого расстояния, или же при касании, на ощупь, например: Налитая дождями вода на шоссе зыбилась на ветру и рябила киноварью (Б. Пастернак, Аоктор Живаго); Она сльишит, как Аида почти бесшумно входит в квартиру, как проскакивает в ванную, как течет вода из душа (В. Кунин, Ребро Адама); Несколько раз Гусев ложился, зарьввваясь лииом в холодный песок, итобы освежить хоть парами влаги запекшийся рот (А. Толстой, Аэлита).

Синоним влага, в отличие от вода, используется также в специальных метеорологических текстах, обозначая субстанцию, содержашуюся в атмосфере, например: Возникает небывалая масса снежсных и дождевьх облаков, несущих избътток влаги и холода (Уппсальский корпус); Атлантические массы воздуха, проходя с запада на восток в Субарктике, несут основной запас влаги на высоте 300-600 м (Уппсальский корпус).

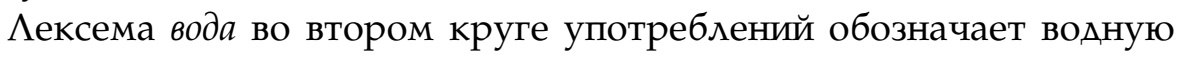
поверхность, например: И вот он едет по приморской дороге и вдруг видит, ито недалеко от берега на воде сидит невиданная в наших краях черная птица с длинной шеей (Ф. Искандер, Сандро из Черема); Пльли по воде стоги сена, бревна, обломки изб и, достигнув плотины, с треском сталкивались друг с другом, ныряли, опять выпльввали и сбивались в куиу в одном месте (М. Е. Салтыков-Щедрин, История одного города).

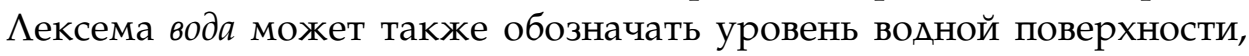
например: низкая «высокая» вода; Вода поднялась «опустилась» до критической отметки.

Иексема влага во втором круге употреблений обозначает слезы или тонкую пелену слез на глазах, например: Она сильно покраснела, и вдруг ее глаза загорелись слезами - я так явственно видел, как темное 
нижнее веко налилось блестящей влагой (В. Набоков, Соглядатай); Из глаз рассказиика вытекала влага, и он был взволнован (Вен. Ерофеев, Москва - Петушки); Илья Андреии бъл немножско красен от вина

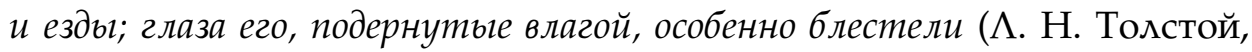
Война и мир).

Проводя итоги всему вышесказанному, можно утверждать, что семантические различия между синонимами вода и влага могут частично или полностью нейтрализироваться только в следующих условиях: во-первых, когда речь идет о небольшом количестве жидкости, например: капля воды «влаги»; во-вторых, когда речь идет о возможности деформирующего воздействия жидкости при попадении ее на объект, например: Специальный крем защищает обувь от водь «влаги»; в-третьих, в составе сложных наименований, например: водо- «влаго-» непроницаемьй, водо- «влаго-» отталкивающий.

\title{
SEMANTIC RELATIONS OF A SUPERORDINATE WORD IN THE CONCEPT OF «WATER» IN THE RUSSIAN LANGUAGE (SYNONYMIA)
}

\begin{abstract}
Summary
The article presents a fragment of the linguistic image of the world, i.e. the concept of «water». The author is interested in the relations occurring between the word naming a concept and its synonyms. The system of lexemes meanings and a typical cohesion connected with it compose a manner of classifying the world characteristic for a specific language. The analyzed synonymic sequence is composed of two lexemes: вода and влага. The research revealed that synonyms $в о д а$ and влага can be used interchangeably only when they name a small amount of liquid (капля воды «влаги»), (капля водь «влаги»), describe a destructive operation of a liquid (Специальный крем защищает обувь от воды «влаги»), or when they constitute a part of compound words (водо- «влаго-» непроницаемьй, водо- «влаго-» отталкивающий).
\end{abstract}

Key words: cognitive linguistics, a linguistic image of the world, a concept, synonymia 


\section{RELACJE SEMANTYCZNE NADRZĘDNEGO WYRAZU KONCEPTU «WODA»W JĘZYKU ROSYJSKIM (SYNONIMIA)}

\section{Streszczenie}

Artykuł prezentuje fragment językowego obrazu świata, a mianowicie koncept «woda». Przedmiotem zainteresowania są relacje zachodzące między wyrazem nazywającym koncept i jego synonimami. Układ znaczeń leksemów oraz związana z tym typowa łączliwość składają się na charakterystyczny dla danego języka sposób klasyfikowania świata. Analizowany ciąg synonimiczny składa się z dwóch leksemów - вода і влага. Jak wykazały badania, synonimy вода i влага mogą być używane wymiennie tylko wtedy, gdy nazywają niewielką ilość cieczy (капля водьı «влаги»), gdy mówi się o niszczącym działaniu cieczy (Специальньıй крем зашищает обувь от водьı «влаги») oraz gdy są częścią wyrazów złożonych (водо- «влаго-» непроницаемьй, водо- «влаго-» отталкивающий).

Słowa kluczowe: językoznawstwo kognitywne, językowy obraz świata, koncept, synonimia 